\title{
In vitro evaluation of the microhardness of bovine enamel exposed to acid solutions after bleaching
}

\section{Caio Gorgulho Zanet ${ }^{(a)}$} Marcelo Fava ${ }^{(b)}$

Levy Anderson César Alves ${ }^{(b)}$

(a) Department of Prosthodontics and Integrated Clinics, College of Dentistry, Ibirapuera University - UNIB, São Paulo, SP, Brazil.

(b) Department of Orthodontics and Pediatric Dentistry, School of Dentistry of São José dos Campos, State University of São Paulo (UNESP), São José dos Campos, SP, Brazil.

Declaration of Interests: The authors certify that they have no commercial or associative interest that represents a conflict of interest in connection with the manuscript.

\section{Corresponding author:}

Levy Anderson César Alves

Email: levy_anderson@yahoo.com

Received for publication on Aug 16, 2011 Accepted for publication on Oct 20, 2011

\begin{abstract}
Acid erosion is a superficial loss of enamel caused by chemical processes that do not involve bacteria. Intrinsic and extrinsic factors, such as the presence of acid substances in the oral cavity, may cause a $\mathrm{pH}$ reduction, thus potentially increasing acid erosion. The aim of this study was to evaluate the microhardness of bleached and unbleached bovine enamel after immersion in a soda beverage, artificial powder juice and hydrochloric acid. The results obtained for the variables of exposure time, acid solution and substrate condition (bleached or unbleached enamel) were statistically analyzed by the ANOVA and Tukey tests. It was concluded that a decrease in microhardness renders dental structures more susceptible to erosion and mineral loss, and that teeth left unbleached show higher values of microhardness compared to bleached teeth.
\end{abstract}

Descriptors: Dental Enamel; Tooth Erosion; Tooth Bleaching.

\section{Introduction}

The twenty-first century has been marked by an increasing concern for oral health and esthetics, leading to a greater number of patients seeking cosmetic dental procedures, particularly dental bleaching. ${ }^{1,2}$

There are many bleaching materials available on the market, ranging from over-the-counter products to sophisticated in-office bleaching systems. ${ }^{3}$ However, the deleterious effects of these bleaching agents on the dental structure vary, and are related to agent composition and concentration, ${ }^{4,5}$ prescribed use instructions, time of exposure, $\mathrm{pH}$ values and type of solutions used..$^{6-8}$

Some of these factors have been connected to dental loss, and, when this occurs, loss of structural material caused by non-carious lesions, such as attrition, abrasion and erosion, is also involved. ${ }^{9}$

Dental erosion is the result of loss of dental hard tissues etched away from the tooth surface by acid or chelating agents. Although the term corrosion is used to describe wear induced by chemical degradation, the terms dental erosion or erosive tooth wear have been widely used in the literature. ${ }^{10}$ The acid substances responsible for this process are not produced by the oral microbiota; on the contrary, they may be produced by gastroesophageal disorders, an acid diet, and also by other substances, such as bleaching products. ${ }^{11,12}$

The factors responsible for dental structural loss may be classified as 
extrinsic and intrinsic. Intrinsic factors have been recently related to anorexia and bulimia, as well as to other gastroesophageal disorders. Extrinsic causes involve the consumption of acidic beverages and the increasing use of bleaching products. ${ }^{13}$

Dental wear can originate from any type of psychosomatic disorder, such as anorexia and bulimia, which often occur concomitantly. However, only bulimia has been closely related to erosion. This disorder is invariably associated with an uncontrolled ingestion of large amounts of food, followed by immediate voluntary or involuntary vomiting. ${ }^{14,15}$ The main factor causing tooth demineralization and consequent erosion of dental structures has been the presence of gastric acid (hydrochloric acid) in the oral cavity during and after vomiting episodes. ${ }^{11,16}$ However, tooth wear may also be caused by extrinsic factors, such as the misuse of acidic dietary products. There is no diagnostic device available to clinically detect and quantify dental erosion at an early state; therefore, clinical appearance is the most important sign used for early diagnosis of erosive lesions. ${ }^{10}$

The aim of this in vitro study was to evaluate the superficial microhardness of bovine dental enamel, previously bleached with a $35 \%$ hydrogen peroxide solution or left unbleached, and then exposed to a diet cola soft drink, an artificial powder juice containing sodium citrate, and gastric juice (no enzyme), for 7, 14 and 21 days.

\section{Methodology}

The present study was approved by the Research Ethics Committee, State University of São Paulo (UNESP), São José dos Campos, Brazil (approval no. 13/2007- PA/CEP). A total of sixty freshly extracted bovine incisor teeth were used in the experiment (mean age of the animals: 3 years) (Matadouro Mantiqueira, São José dos Campos, Brazil). The tooth roots were removed by transversally cutting the tooth with a carborundum disc.

The pulp tissue was extirpated with endodontic files, and the pulp chamber was constantly irrigated with physiological solution to remove any remaining material. The specimens were placed in a silicone matrix, into which chemically activated acrylic resin (Jet-Clássico, São Paulo, Brazil) was inserted, leaving the buccal aspects of the teeth exposed. The enamel surface of each specimen was serially polished under refrigeration, using a circular polishing machine (Eros, São Paulo, Brazil), in decreasing order of disc granulation $(400,600,800$, and 1200$)$ to obtain flat, standardized enamel surfaces.

All 60 specimens were randomly divided into two groups of 30 samples each:

- Group NHP: Samples were stored in artificial saliva for a period of 14 days, without any previous hydrogen peroxide treatment.

- Group HP: Samples were treated with a 35\% hydrogen peroxide solution (Pola Office Bulk Kit, SDI - Southern Dental Industries, Bayswater, Australia), according to the manufacturer's protocol, and then stored in artificial saliva for a period of 7 days.

After this period, the specimens were submitted to an initial microhardness measurement. A second treatment with $35 \%$ hydrogen peroxide was then carried out and the specimens were maintained in artificial saliva for an additional period of 7 days, after which another microhardness reading was performed and recorded.

The specimens of groups NHP and HP were then subdivided into 6 groups, each of which was exposed to one of the respectively assigned acid solutions ${ }^{17}$ for 5 minutes and stored in artificial saliva (Byofórmula, São José dos Campos, Brazil) for 23 hours and 55 minutes, to complete a period of 24 hours. This process was repeated for 7 days in a row, and then all specimens were submitted to a third microhardness measurement. This 7-day regimen was repeated twice and another two microhardness measurements were performed and recorded with the aim of completing a 21-day exposure cycle for the experiment.

All specimens were analyzed according to the indentation technique, using a microhardness tester (FM 700, FutureTech Corp., Tokyo, Japan) under a 50-g load for a period of 10 seconds. Specimens were positioned perpendicularly to the long axis of the indenter, and three indentation measurements were recorded for each evaluation. The mean values 
were then calculated.

The results obtained for each group were statistically analyzed separately. In the first part of the experiment, two-way analysis of variance (ANOVA) was performed, and the interaction between parameters was evaluated, namely, presence or absence of a bleaching agent, and number of bleaching sessions - first session, storage in artificial saliva for 7 days, and second session, storage in artificial saliva, for a total of 14 days.

In the second part of the experiment, three-way analysis of variance (ANOVA) was used: 2 factors among the groups and 1 factor within the groups. The factors considered among the groups were tooth condition (bleached or unbleached) and acid solutions (soft drink, juice or $\mathrm{HCl}$ ). The factor repeated within groups was the immersion period in acid solution (7, 14 and 21 days).

The Tukey's test was performed at a 5\% level of significance, in order to assess whether the group results were homogeneous.

\section{Results}

Evaluation of the mean and standard deviation results (Table 1) for the main effects on enamel microhardness revealed statistical significance for the bleaching agent, since a greater microhardness mean value $(227.09 \pm 42.30 \mathrm{HV})$ was observed for the unbleached condition, as compared to the bleached condition (179.14 $\pm 40.07 \mathrm{HV})$.

Regarding the number of bleaching sessions ( $\mathrm{Ta}-$ ble 2), the single-session condition resulted in a greater mean microhardness value (198.32 $\pm 43.81 \mathrm{HV})$ compared to the value obtained after two sessions $(159.97 \pm 30.67 \mathrm{HV})$.

When comparing the Tukey's Test $(5 \%)$ values obtained within the groups, the smallest resistance was observed for the second bleaching session after 14 days of storage in artificial saliva $(159.97 \pm 30.67 \mathrm{HV})$, which was statistically different from that observed for the other three experimental conditions (Table 3).

After the first part of the experiment, the values obtained for the control group were defined as the values obtained after 14 days, for both bleached and unbleached teeth. The microhardness values for the
Table 1 - Microhardness (HV) mean and standard deviation values for bleached and unbleached conditions.

\begin{tabular}{c|c|c|c|c|c}
\hline Variable & Bleached & $\mathrm{N}$ & Mean & SD & $\begin{array}{c}\text { Variation } \\
\text { Coefficient (\%) }\end{array}$ \\
\hline \multirow{2}{*}{$\mathrm{HV}$} & no & 30 & 227.09 & 42.30 & 18.63 \\
\cline { 2 - 6 } & yes & 30 & 179.14 & 40.07 & 22.37 \\
\hline
\end{tabular}

Table 2 - Microhardness (HV) mean and standard deviation values for bleached and unbleached conditions.

\begin{tabular}{l|c|l|l|c}
\hline \multicolumn{1}{c|}{ Variable } & N & \multicolumn{1}{c|}{ Mean } & \multicolumn{1}{c|}{ SD } & $\begin{array}{c}\text { Variation } \\
\text { Coefficient (\%) }\end{array}$ \\
\hline Unbleached (7 d) & 15 & 233.5 & 50.5 & 21.64 \\
\hline Unbleached (14 d) & 15 & 220.64 & 32.61 & 14.78 \\
\hline Bleached (7 d) & 15 & 198.32 & 40.0 & 20.15 \\
\hline Bleached (14 d) & 15 & 159.97 & 30.67 & 19.17 \\
\hline
\end{tabular}

Table 3 - Tukey's Test (5\%) results for bleached and unbleached conditions.

\begin{tabular}{c|c|c|c|c}
\hline Bleached & Evaluation period (days) & Mean & \multicolumn{2}{|c}{$\begin{array}{c}\text { Homogeneous } \\
\text { Groups }\end{array}$} \\
\hline No & 7 & 233.54 & A & \\
\hline No & 14 & 220.64 & A & \\
\hline Yes & 7 & 198.32 & A & \\
\hline Yes & 14 & 159.97 & & B \\
\hline
\end{tabular}

control group were compared to the post-immersion values obtained for all acid solutions used in the experiment.

\section{Discussion}

Physical contact between bleached teeth and acid substances, generally contained in foods or produced by gastroesophageal disturbances, may result in severe enamel demineralization. ${ }^{10}$ Therefore, scientific studies are needed to elucidate the relationship between dental bleaching and dental erosion. In such studies, it is important that human or bovine teeth be stored and prepared appropriately.

In the present study, the effect of acid substances on the enamel surface of freshly extracted bovine teeth submitted to bleaching or left unbleached was investigated. We chose to use bovine teeth because a great number of specimens were required, and also 
because some variables, such as age range, could be better controlled. Additionally, the samples could be stored for the same period of time. Although the enamel of bovine teeth is more permeable than that of human teeth, the experiment was otherwise standardized according to the criteria previously mentioned. ${ }^{18}$

Earlier studies have shown that the dissolution degree of bovine enamel is three times greater than that of human enamel. ${ }^{18,19}$ In addition, bovine enamel can be significantly affected by acid substances. Nevertheless, even though there are differences between human and bovine enamel, bovine teeth may be considered acceptable considering that, should any bovine-specific interference occur, it will produce equal effects across the experimental groups, thus rendering the overall experiment unaffected.

The $\mathrm{pH}$ values of the beverages used in the experiment ranged from 2.75 to 3.29 , and the beverages were mainly composed of citric, phosphoric, ${ }^{20}$ tartaric, maleic, and tannic acids, and contained specific flavonoids, such as, catecholamines. ${ }^{21}$ Sodium citrate can also be found in some drinks, and plays an important mineral and preservative role.

Hydrogen peroxide is one of the most important bleaching products available today, and is a substance capable of altering the enamel surface. Its action is generally a result of its oxidizing properties, which remove organic material without dissolving the enamel matrix, eventually producing clearer compounds. However, long exposure periods could result in dissolution of the enamel matrix. ${ }^{22}$

Other studies have reported high solubility and decreased resistance of enamel, dentin and cementum, when exposed to bleaching agents. Demineralization, protein matrix destruction and deposition of small amorphous mineral precipitates have been reported to affect prism periphery. ${ }^{23-25}$

The results of this study show that the action of the bleaching agent in the first part of the experiment (Table 2) was significant. The mean microhardness value $(227.09 \pm 42.30)$ for the unbleached teeth was greater than that observed for the bleached teeth $(179.14 \pm 40.07)$. Table 3 shows that the microhardness value obtained for the first bleaching session $(198.32 \pm 48.21)$ was greater than that obtained for the second one $(159.97 \pm 30.67)$.

Table 3 also shows an intra-group comparison of the mean values found for the 4 experimental conditions in the first part of the experiment. Statistically similar values were observed between unbleached teeth stored in saliva for a period of 7 and 14 days, and bleached teeth stored in saliva for a period of 7 days. The second bleaching session (with an additional 7-day storage time in artificial saliva, for a total of 14 storage days) showed a smaller, statistically different value $(159.97 \pm 30.67)$ compared to that of the other groups. According to Rodrigues, ${ }^{26}$ the contact time between hydrogen peroxide and dental enamel can significantly affect enamel hardness.

The control group values, considered in the second part of the experiment, were those found for the samples before they were immersed in the acid substances. Barbour et al. ${ }^{9}$ suggested a linear relation between enamel microhardness and the $\mathrm{pH}$ values of the solutions. The presence of poly-basic acids promotes calcium chelation, leading to dissolution of dental enamel.

Moreover, the removal of superficial enamel performed during specimen preparation may have influenced the demineralization process, owing to the exposure of a more reactive type of enamel. ${ }^{19}$

The present study and other reports found in the literature suggest that bovine enamel could be affected by chemical substances, depending on substance composition and acidity level, as well as on the time of exposure to these substances. ${ }^{20,27}$ Thus, deleterious effects on dental enamel can be observed when it comes into frequent contact with acidic drinks, particularly when associated to a low saliva flow rate and poor oral hygiene habits.

The microhardness values of the unbleached specimens followed a decreasing trend throughout the immersion periods of 7, 14 and 21 days, and were significantly different.

There were no significant statistical differences between the cola beverage and the juice groups. At 21 days, all solutions presented statistically different values, and it could be observed that the demineralization caused by the acid substances was more severe for bleached teeth ${ }^{28}$ as compared to the unbleached samples. The longer the contact time be- 
tween enamel surface and the solutions, the greater the demineralization of the enamel surface.

Further investigations are required to better elucidate the acid demineralization process. We suggest that such studies include the variables of consumption frequency, swallowing speed, consumption temperature, period of exposure to gingival fluid and remineralization ability.

\section{References}

1. Spyrides GM, Naressi SCM, Rodrigues JR, Araújo MAM. Clareamento de dentes vitalizados. J Bras Odont Clin. 1998;2(9):15-20.

2. Dietschi D, Benbachir N, Krejci I. In vitro colorimetric evaluation of the efficacy of home bleaching and over-the-counter bleaching products. Quintessence Int. 2010 June;4(6):505-16.

3. Ghulman MA, Awad MA. Effect of different bleaching materials on surface roughness and microhardness of fiber-reinforced composite fixed restorations. Int J Clin Dent. 2011 Mar;3(4):253-74.

4. Akal N, Over H, Olmez A, Bodur H. Effects of carbamide peroxide containing bleaching agents on the morphology and surface hardness of enamel. J Clin Pediatr Dent. 2001 Summer;25(4):293-6.

5. Attin T, Betke H, Schippan F, Wiegand A. Potential of fluoridated carbamide peroxide gels to support post-bleaching enamel re-hardening. J Dent. 2007 Sep;35(9):755-9.

6. Attin T, Koide U, Buchalla W, Schaller HG, Kielbassa AM, Hellwig E. Correlation of microhardness and wear in differently eroded bovine dental enamel. Arch Oral Biol. 1997 Mar;42(3):243-50.

7. Ballal V, Bhat KS. Restoration of extensive erosion associated with cola soft drink using direct composite Veneers - a case report. Int J Clin Dent 2010 Mar;3(3):211-7.

8. Barbour ME, Parker DM, Allen GC, Jandt KD. Enamel dissolution in citric acid as a function of calcium and phosphate concentrations and degree of saturation with respect to hydroxyapatite. Eur J Oral Sci. 2003 Oct; 111 (5): 428-33.

9. Barbour ME, Parker DM, Allen GC, Jandt KD. Human enamel dissolution in citric acid as function of $\mathrm{pH}$ the range $2.30 \leq \mathrm{pH} \leq 6.30$ a nanoindentation study. Eur J Oral Sci. 2003 Jun; 111 (3):258-62.

10. Serra MC, Messias DCF, Turssi CP. Control of erosive tooth wear: possibilities and rationale. Braz Oral Res. 2009;23(1):4955.

11. Barbour ME, Parker DM, Allen GC, Jandt KD. Human enamel erosion in constant composition citric acid solutions as a funcion of degree of saturation with respect to hydroxyapatite. J Oral Rehabil. 2005 Jan;32(1):16-21.

\section{Conclusions}

- The time period of contact between acid solutions and teeth directly affected the structural demineralization of enamel: the longer the exposure time, the greater the surface demineralization.

- The enamel microhardness values for unbleached teeth were higher than those of bleached teeth.

12. Bartlett DW, Coward PY. Comparison of the erosive potential of gastric juice and a carbonated drink in vitro. J Oral Rehabil. 2001 Nov;28(11):1045-7.

13. Erickson PR, Alevizos DL, Rindelaub DJ. Soft Drinks: hard on teeth. Northwest Dent. 2001 Mar-Apr;80(2):15-9.

14. Bartlett DW, Evans DF, Smith BGN. The relationship between gastro-oesophageal reflux disease and dental erosion. J Oral Rehabil. 1996 May;23 (5):289-97.

15. Bitter NC. A scanning electron microscope study of the longterm effect of bleaching agents on the enamel surface in vivo. Gen Dent. 1998 Jan-Feb;46(1):84-8.

16. Bitter NC, Sanders JL. The effect of four bleaching agents on enamel surface a scanning electron microscopic study. Quintessence Int. 1993 Nov;24(11):817-24.

17. Bizhang M, Seemann R, Duve G, Romhild G, Altenburger JM, Jahn KR, et al. Desmineralization effects of 2 bleaching procedures on enamel surfaces with and without post-treatment fluoride application. Oper Dent. 2006 Nov-Dec;31(6):705-9.

18. Brown CJ, Smith G, Shaw L, Parry J, Smith AJ. The erosive potential of flavoured sparkling water drinks. Int J Paediatr Dent. 2007 Mar; 17 (2):86-91.

19. Brunton PA, Hussain A. The erosive effect of herbal tea on dental enamel. J Dent. 2001 Jul;29(8):517-20.

20. Cairns AM, Watson M, Creanor SL, Foye RH. The pH and titratable acidity of a range of diluting drinks and their potential effects on dental erosion. J Dent. 2002 Sep-Nov;30(7-8):313-7.

21. Dalle Grave R, Calugi S. Eating disorder not otherwise specified in an inpatient unit: the impact of altering the DSM-IV criteria for anorexia and bulimia nervosa. Eur Eat Disord Rev. 2007 Sep;15(5):340-9.

22. Duggal MS, Tahmassebi JF, Pollard MA. Effect of addition of $0.103 \%$ citrate to a blackcurrant drink on plaque $\mathrm{pH}$ in vivo. Caries Res.1995 Mar;29(1):75-9.

23. Dugmore CR, Rock WP. A multifactorial analysis of factors associated with dental erosion. Br Dent J. 2004 Mar;196(5):2836.

24. Duke SA, Molyneux K, Jackson RJ. The effect of citrate in drinks on plaque pH. Br Dent J. 1989 Jun;166(7):327-30. 
25. Efeoglu N, Wood DJ, Efeoglu C. Thirty-five percent carbamide peroxide application causes in vitro demineralization of enamel. Dent Mater. 2007 Jul;23(7):900-4.

26. Rodrigues JA, Basting RT, Serra MC, Rodrigues Júnior AL. Effects of $10 \%$ carbamide peroxide bleaching materials on enamel microhardness. Am J Dent. 2001 Apr;14(2):67-71.
27. Fasanaro TS. Bleaching teeth: history, chemicals, and methods used for common tooth discolorations. J Esthet Dent. 1992 May-Jun;4(3):71-8.

28. Grobler SR, Senekal PJ, Laubscher JA. In vitro demineralization of enamel by orange juice, apple juice, Pepsi Cola and Diet Pepsi Cola. Clin Prev. Dent. 1990 Dec;12(5):5-9. 